\title{
REVISITANDO OS EFEITOS DE LUGAR: segregação e acesso ao mercado de trabalho em uma metrópole brasileira
}

\author{
Ângela Borges* \\ Inaiá Carvalho * *
}

\begin{abstract}
Este artigo se propõe a discutir o denominado "efeito território", compreendido como os benefícios ou prejuízos que afetam alguns grupos sociais em decorrência de sua localização no espaço urbano, analisando como o local de moradia interfere sobre o acesso e a incorporação ao mercado de trabalho, com base em uma pesquisa efetuada na terceira maior capital brasileira, a cidade de Salvador. Para tanto, ele começa se reportando à literatura existente sobre esse fenômeno e às discussões correntes sobre os impactos adversos da segregação. Apresenta, a seguir, as especificidades de Salvador do ponto de vista da ocupação e diferenciação do seu território e de suas condições ocupacionais. Por fim, com base em tabulações especiais da RAIS e do Censo de 2010, devidamente espacializadas, o texto evidencia como o "efeito território" opera de forma adversa à população que se concentra nas periferias pobres, mais distantes e menos equipadas, somando-se a outros fatores e contribuindo para a vulnerabilidade ocupacional de seus moradores e para a reprodução das desigualdades sociais.
\end{abstract}

Palavras-chave: Segregação socioespacial. "Efeito território”. Emprego e desemprego. Salvador.

\section{INTRODUÇÃO}

Em um capítulo do seu livro A Miséria do Mundo, Bourdieu (1997) faz uma acurada análise sobre como o espaço social se retraduz no espaço físico, exprimindo as hierarquias e distâncias sociais e interferindo sobre a disponibilidade e distribuição de bens públicos e privados e sobre as oportunidades de sua apropriação por diferentes grupos e classes sociais. Tomando de empréstimo o título do referido capítulo, o presente trabalho discute como a segregação socioespacial interfere sobre as condições de acesso e incorporação ao mercado de trabalho, a partir de uma pesquisa efetuada na terceira maior metrópole brasileira, a cidade de Salvador.

O fenômeno da segregação socioespacial, que pode ser definido como a distribuição desigual dos diversos grupos sociais no espaço

* Universidade Católica do Salvador (UCSal). Programa de Pós-Graduação em Políticas Sociais e Cidadania. Avenida Cardeal da Silva, 205. Federação. Cep: 41940450 Salvador - Bahia - Brasil. angelborges@uol.com.br

** Universidade Católica do Salvador (UCSal). Programa de Pós-Graduação em Políticas Sociais e Cidadania.

Avenida Cardeal da Silva, 205. Federação. Cep: 41940450.

Salvador - Bahia - Brasil. inaiammc@ufba.br das cidades, com a concentração desses grupos em determinadas áreas e a diferenciação desse espaço e seus efeitos sobre a vida dos moradores, tem despertado o interesse dos pesquisadores desde os primeiros estudos da Escola de Chicago. O crescimento e a concentração da pobreza nos guetos negros das grandes cidades americanas, que marcaram a segunda metade do século passado, renovaram o interesse por essa discussão, e, na esteira do clássico estudo de Wilson (1987), multiplicaram-se trabalhos como o de Jargowsky (1996), Small e Newman (2001), ou Wacquant $(1997,2008)$. Estudos sobre esse fenômeno também se desenvolveram na França e em outros países europeus, onde a diferenciação da cidade e a segregação residencial passaram a ser enfocadas do ponto de vista das distintas categorias socioeconômicas e, nos últimos anos, essa discussão foi revigorada pela difusão do paradigma das cidades globais, que teriam, entre suas características, uma tendência à dualização social e urbana (Preteceille, 2003, 2013).

No Brasil e na América Latina, embora as cidades tradicionalmente venham sendo pensadas como espaços de intensa desigualda- 
de, periferização, e “espoliação urbana” (Kowarick, 1980), a associação entre a segregação e a problemática norte-americana de tradução espacial da questão racial levou a uma utilização relativamente tardia desse conceito. Mais recentemente, porém, com uma discussão mais refinada sobre o seu significado, intensidade, procedimentos de medida, determinantes etnorraciais ou sócio-ocupacionais mais imediatos e semelhanças e diferenças quanto à sua manifestação, diversos estudos vêm sendo desenvolvidos com esse enfoque. Tais estudos vêm se somando a uma ampla literatura internacional sobre o referido fenômeno e sobre o denominado "efeito território" (Andrade; Silveira, 2013), ou "efeito bairro" (Sabatini; Wormald; Rassa, 2013), compreendidos como os benefícios ou prejuízos socioeconômicos que afetam alguns grupos sociais em função da sua localização no espaço das cidades e sobre os seus impactos quanto à situação e reprodução da pobreza, da vulnerabilidade e das desigualdades sociais (Cf. Bourdieu, 1997; Flores, 2006; Kaztman, 2001; Kaztman; Retamoso, 2005; Marques, 2010; Molinatti, 2013; Ribeiro; Rodrigues; Nery, 2014; Sabatini; Wormald; Rassa, 2013; Small; Newman, 2001; Telles; Cabanes, 2006; Vignoli, 2008; Wacquant, 1997, 2008; Wilson, 1987).

Alguns desses estudos enfatizam os imลे pactos do entorno sobre a trama social, o processo de socialização coletiva, ${ }^{1}$ a influência สี dos pares sobre as novas gerações e sua maior lar, a gravidez precoce ou o envolvimento com $\underset{7}{ }$ drogas e com a criminalidade. Outros abordam के o estreitamento das redes e do capital social, \& assim como a distribuição dos serviços básicos iे e de outros recursos no espaço urbano. Con$>$ figurando uma "geografia de oportunidades", essa distribuição termina por interferir nega-

${ }^{1}$ Alguns autores se reportam, inclusive, à socialização insTitucional, envolvendo a forma como os moradores de áre-

色 as segregadas são vistos e tratados pelas autoridades pú-

blicas. Ao desacreditar nas potencialidades das crianças e

jovens que residem nessas áreas, por exemplo, professores da rede pública terminariam por deixar de incentivá-los a alcançar maiores níveis de escolaridade. tivamente sobre as condições de vida dos moradores das áreas em discussão, uma vez que elas são normalmente mais restritas e precárias nessas áreas.

No campo da educação, por exemplo, investigações efetuadas em diversos países constataram a tendência das escolas públicas de se diferenciarem conforme a composição da área onde estão localizadas, com sérias desvantagens para aquelas que servem aos moradores das áreas pobres da cidade. No Brasil e na América Latina, estudos como os de Burgos (2009), Ribeiro e Katzman (2008), Flores (2006) ou Ribeiro et al. (2010) têm comprovado essa realidade. Com isso, essas escolas não conseguem propiciar a seus alunos a aprendizagem e o avanço necessário para o alcance de credenciais educacionais exigidas crescentemente para a conquista de melhores condições no mercado de trabalho.

Além disso, como para trabalhadores de menor escolaridade e renda, as informações e o acesso às oportunidades de trabalho dependem, principalmente, de contatos e indicações pessoais, a homogeneidade de vizinhança e a estreiteza das redes sociais ${ }^{2}$ também representam um fator adverso à incorporação produtiva dos referidos moradores. Algumas das áreas em discussão, desvalorizadas e marcadas pela informalidade, pela menor presença do Estado e das instituições de controle e segurança pública (ou por uma atuação repressiva e violenta das mesmas sobre os seus moradores), têm se tornado presas do tráfico de drogas e do crime organizado. Associado ao crescimento das desigualdades, à superposição das carências e à falta de perspectivas para muitos jovens de famílias pobres, isto têm contribuído para a degradação dos padrões de sociabilidade e para o crescimento da violência, transformando essas áreas em "territórios penalizados e penalizadores”, situados no mais baixo nível da estrutura urbana e portadores de um estigma

2 No caso do Brasil, um maior acesso dos jovens das camadas populares à internet e às redes sociais pode estar começando a atenuar esse fato. 
residencial poderoso (Wacquant, 2008). Construindo e consolidando uma visão negativa dos referidos espaços e dos seus moradores, esse estigma também afeta negativamente suas possibilidades de integração produtiva, notadamente no caso dos jovens.

Diversos estudos têm destacado os efeitos dos fenômenos assinalados sobre as possibilidades e condições de ocupação. Em pesquisa realizada na capital e em outras cidades chilenas, por exemplo, Sabatini, Wormald e Rassa (2013) constataram como o isolamento espacial e social lhes é adverso, contribuindo para a inatividade, para o trabalho precário, o desemprego e a persistência da pobreza. Especialmente no caso das mulheres, que têm maiores restrições e dificuldades para se deslocar em decorrência de fatores como a necessidade de conciliar o trabalho com as responsabilidades domésticas e os riscos de se expor a zonas e horários considerados como perigosos, nesse deslocamento.

Gomes e Amitrano (2005) também comprovaram que, independentemente de outros atributos sociais (como sexo, cor, juventude ou escolaridade), a população residente nas áreas mais pobres também convivia com maiores taxas de desemprego; entre outros fatores, isso estava associado a uma pequena oferta de postos formais nas referidas áreas, e, dentro da oferta existente, as remunerações eram mais baixas, levando os moradores pobres a arcar com problemas e maiores custos de transporte e gasto de tempo nos deslocamentos para os bairros centrais a fim de ampliar suas oportunidades de trabalho.

Além disso, a integração ocupacional, as condições de vida dos segmentos sociais em apreço e a própria dinâmica mais ampla das cidades também são influenciadas negativamente pela distribuição dos estabelecimentos comerciais e de serviços e das oportunidades de emprego e de obtenção de renda no espaço urbano, devido à crescente distância entre os locais de residência e os de trabalho, estudo e acesso aos diversos serviços por parte de grande maioria da população. Como se sabe, o processo de crescimento das cidades tende a combinar a expansão e a dispersão física da malha urbana com a concentração dos fluxos e atividades em determinados pontos desse território e a agregação de novas centralidades ao centro tradicional.

Analisando essa questão, Fonsêca (2012) assinala como, nos países desenvolvidos, a localização das novas centralidades está associada aos principais fluxos da rede viária, aos grandes terminais de transporte de massa, à indução do poder público e à implantação de grandes equipamentos em áreas escolhidas por investidores privados. Em metrópoles como as brasileiras, a infraestrutura também pesa na determinação das decisões locacionais, o que leva à concentração de investimentos nos bairros de renda média e alta, que são mais bem equipados, uma decisão locacional que é também influenciada pelas preferências dos trabalhadores mais qualificados que ocupam as posições-chave dos processos produtivos por trabalharem nas proximidades de suas áreas residenciais. Além desses fatores, que atuam nos diversos países, a concentração do poder aquisitivo nas camadas de renda média e alta, minoritárias, constitui o principal determinante da concentração dos estabelecimentos comerciais e de serviços nos bairros de proximidade residencial desses grupos.

Já nas áreas densamente povoadas e homogêneas, onde reside a grande maioria da população, o baixo poder aquisitivo dos moradores nem sempre é suficiente para estimular o surgimento de subcentros fortes e de maiores oportunidades de emprego formal. Muitas dessas áreas sediam apenas algumas atividades mais diretamente ligadas à reprodução, como bares ou pequenas mercearias, ${ }^{3}$ obrigando os que ali residem a longos deslocamentos para procurar emprego e para trabalhar, dependen-

${ }^{3}$ Nos anos 2000, esse cenário sofreu algumas mudanças não captadas nos dados aqui trabalhados, pois os bairros populares e, sobretudo, suas áreas centrais receberam algumas filiais de redes do comércio e de bancos, atraídos pelo aumento da renda das camadas mais pobres. 
do de um sistema de transportes coletivo lento e precário, e arcando com os custos monetários e não monetários desse deslocamento. Tudo isso pode representar mais um obstáculo à integração produtiva, notadamente no caso daqueles grupos com atributos menos valorizados no mercado de trabalho, como os jovens, os negros, as mulheres e aqueles dotados de menor escolaridade.

Pesquisa realizada pela autora na cidade de São Paulo, a maior metrópole brasileira, constatou a reduzida localização e diferenciação dos estabelecimentos de comércio e serviços na periferia, enquanto as áreas com maior densidade de uso e de fluxos estão localizadas nas regiões próximas ao centro expandido e são ocupadas pela população de maior poder aquisitivo.

Em Salvador, esse desajuste entre o padrão de segregação e a residência em bairros periféricos parece ter esses mesmos efeitos sobre a inserção e as condições ocupacionais de seus moradores, conforme investigação cujos resultados são apresentados a seguir.

\section{SEGREGAÇÃO E MERCADO DE TRABALHO EM SALVADOR}

Como já foi mencionado, Salvador é, atualmente, a terceira maior cidade brasileira, com uma população estimada de 2.902 mil habitantes, marcada por uma significativa pobreza e por históricos problemas ocupacionais. Mesmo após a conjuntura econômica favorável que caracterizou a primeira década deste novo século, com uma queda do desemprego, um crescimento do emprego formal e uma relativa recuperação da remuneração dos trabalhadores, foi constatado pelo Censo de 2010 que a cidade ainda possuía 17,6\% de empregados sem registro formal, $18,7 \%$ de trabalhadores por conta própria (a maioria deles em ocupações precárias e de baixa remuneração) e 1,1\% de trabalhadores não remunerados naquela ocasião. Os serviços domésticos respondiam isoladamente por cerca de 9,1\% da ocupação, e os postos melhor remunerados apareceram em número reduzido, uma vez que $39,4 \%$ dos ocupados percebiam um rendimento mensal de até um salário mínimo (considerando a soma de todos os trabalhos), $68,9 \%$ de até dois salários mínimos e apenas 6,4\% de dez salários mínimos ou mais.

Como se sabe, os problemas de incorporação ao mercado de trabalho não atingem os diversos contingentes de trabalhadores com a mesma intensidade. Atributos como sexo, idade, cor e escolaridade agravam as dificuldades, tornando mais vulneráveis ao desemprego e à informalidade alguns segmentos, como as mulheres, os negros, os jovens e os menos escolarizados, os quais estão sobrerrepresentados nos postos de trabalho de menor qualidade, desprotegidos, inseguros e de baixos rendimentos. A esses atributos somam-se os locais de residência na metrópole, ou seja, os impactos do padrão de segregação e dos "efeitos do lugar" sobre as oportunidades ocupacionais, uma vez que Salvador também se caracteriza por uma intensa desigualdade entre os seus três grandes vetores de expansão, a Orla Marítima Norte, o Miolo e o Subúrbio Ferroviário, no litoral da Baía de Todos os Santos.

O primeiro constitui a área "nobre" de Salvador, local de moradia, serviços e lazer onde se concentram a riqueza, os investimentos públicos, os equipamentos urbanos, os interesses do capital imobiliário, e, como será visto, as oportunidades de trabalho e de obtenção de renda, ainda que elas persistam relevantes no centro tradicional. O segundo, que tem esse nome pela sua localização no centro geográfico do município, começou a ser ocupado com a implantação de conjuntos residenciais para a “classe média baixa” na fase áurea do Sistema Financeiro de Habitação, tendo a sua expansão continuada por loteamentos populares e sucessivas ocupações irregulares, com uma disponibilidade de equipamentos e de serviços bastante restrita. Finalmente, o Subúrbio Ferroviário, que começou a ser habitado com 
a implantação de uma linha férrea, em 1860, constituindo, a partir de 1940, a localização de vários loteamentos populares e ocupações irregulares. Para lá também foram transferidos moradores dos assentamentos erradicados pela Prefeitura da área "nobre" da cidade, de forma que o Subúrbio se transformou em uma das áreas mais carentes da capital baiana, marcado pela precariedade habitacional, pelas deficiências de infraestrutura e serviços básicos, pela pobreza dos seus moradores e, mais recentemente, por altos índices de violência.

Essa apropriação diferenciada do território urbano e os padrões de segregação dela resultantes foram identificados e analisados por Carvalho e Pereira (2008) com base nos dados do Censo de 2000 e na metodologia do Observatório das Metrópoles. Essa metodologia envolveu inicialmente a classificação da população economicamente ativa e sua agregação em categorias ocupacionais mais abrangentes. Em um segundo momento, foi considerada a distribuição dessas categorias no espaço urbano, tendo como recorte territorial áreas definidas por uma agregação de setores censitários utilizado no Censo de 2000 pelo IBGE. ${ }^{4}$ Levando em conta como as diversas categorias estão representadas no território de Salvador, foi elaborada uma tipologia que as classificou como superior, média superior, média, popular, popular inferior, popular operário-agrícola e popular agrícola, de acordo com a composição dos seus moradores.

Na categoria considerada como superior, predominavam os grandes empresários, os dirigentes do setor público e do setor privado, ao lado do grupo denominado como "intelectuais” (profissionais de nível superior, autônomos ou empregados); na média superior, o predomínio era dos "intelectuais"; na média, os profissionais de nível superior se misturavam

${ }^{4}$ Embora se disponha atualmente da tipologia elaborada com dados do Censo de 2010, optou-se por utilizar aquela efetuada com dados do Censo de 2000, considerando que essa última permite uma visão mais detalhada da diferenciação do espaço soteropolitano e que não havia mudanças significativas entre um Censo e outro, nos padrões de sua apropriação social. com pequenos empregadores e trabalhadores em ocupações técnicas, de escritório, ocupações médias de educação e saúde e similares; nas áreas de tipo popular, se concentravam trabalhadores manuais da indústria e do comércio, assim como prestadores de serviços com alguma qualificação; nas classificadas como popular inferior, havia uma conjugação desses trabalhadores com prestadores de serviços não qualificados, trabalhadores domésticos, ambulantes e biscateiros. Como popular-agrícolas foram classificadas aquelas áreas que possuíam uma presença mais significativa de trabalhadores rurais, áreas menos valorizadas e com baixa densidade demográfica, situadas em alguns municípios limítrofes da capital baiana.

Com base nessa classificação, ficou patente a ocupação da Orla Atlântica predominantemente por grandes empregadores, dirigentes e trabalhadores "intelectuais", ressalvando-se alguns enclaves de cunho popular como o Nordeste de Amaralina, a Boca do Rio e o Bairro da Paz. Como já foi mencionado, nesses espaços se concentravam os equipamentos públicos e privados mais importantes, modernos centros de comércio e serviços e grandes equipamentos urbanos (como shoppings centers, parques e centro de convenções), assim como as oportunidades de trabalho e obtenção de renda. Os setores médios também ocupavam essas áreas, assim como o centro tradicional e as áreas mais antigas da cidade.

Já as áreas populares abrigavam a população que não tinha possibilidades de consumir o espaço da cidade moderna nem da cidade tradicional, alojando-se, principalmente, em parcelamentos clandestinos e habitações precariamente construídas no Miolo e (ou) no Subúrbio. Os trabalhadores de subsistência tinham forte presença nessas áreas e em alguns pequenos interstícios da Orla Atlântica, como ilustra o Mapa 1. 


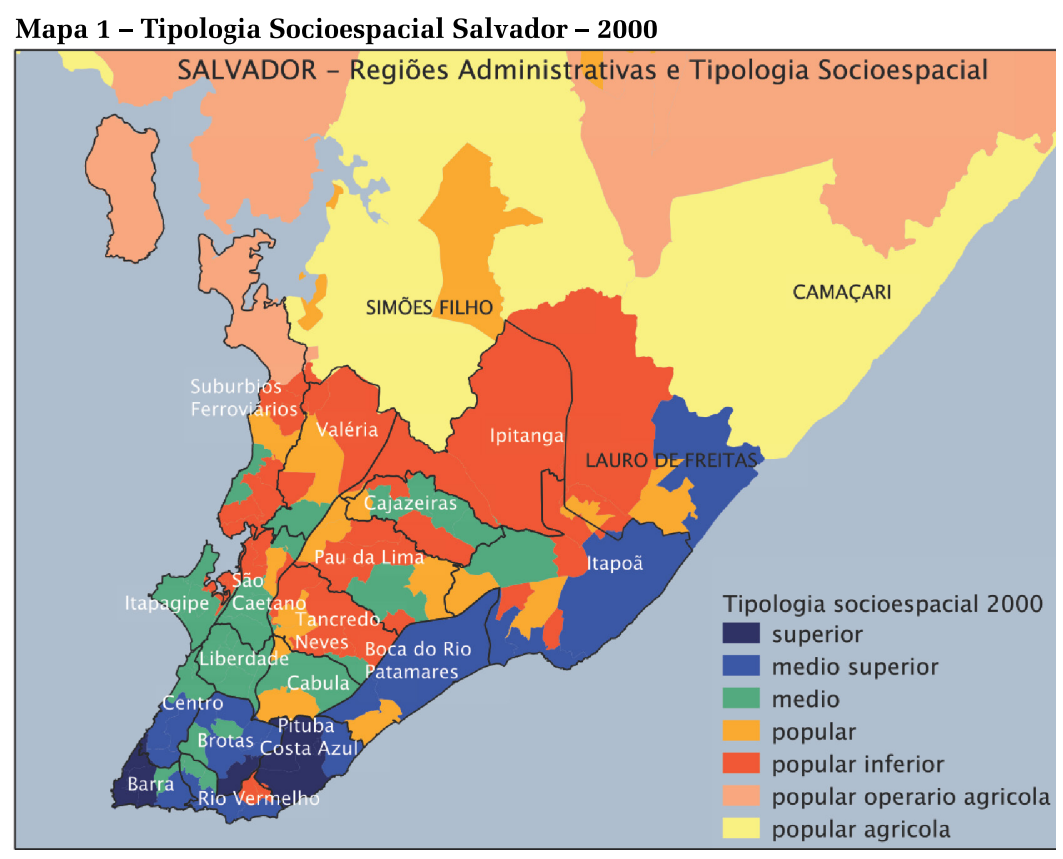

Fonte: IBGE. Censo Demográfico de 2000. (Cf. Carvalho; Pereira, 2008).

\section{“EFEITO TERRITÓRIO”}

Embora Salvador seja marcada pelos problemas de emprego e renda da sua população, esses problemas não atingem da mesma forma todos os moradores, afetando principalmente os portadores de determinados atributos, especialmente quando alguns deles aparecem conjugados, como no caso das mulheres negras ou dos jovens com menor escolaridaڤิ de. Quando se analisam o perfil e a condição ocupacional dos trabalhadores de acordo com que a vulnerabilidade desses contingentes tende a ser acentuada pelo "efeito território".

A moradia em áreas homogeneamente pobres e segregadas tem efeitos adversos sobre o acesso e a incorporação ao mercado de trabalho, por razões que incluem um reduzido acesso a escolas de melhor qualidade, o estreitamento das redes e um menor acúmulo de capital social, estigmas que afetam moradores de bairros discriminados e a própria concentração das oportunidades e postos de trabalho nas áreas centrais e mais afluentes.

Em Salvador como em outras metrópoles alguns desses fenômenos são bastante evidentes. Enquanto as escolas mais bem equipadas e avaliadas se concentram na área central e na Orla Atlântica, nas áreas populares e periféricas predominam aquelas em mais precárias condições, o que contribui para o aumento do insucesso e do abandono escolar. A estreiteza das redes (reduzidas, muitas vezes, a familiares e vizinhos na mesma condição de vulnerabilidade) também foi constatada em estudos como o de Arantes (2007), assim como o preconceito e a discriminação dos empregadores contra jovens residentes em bairros percebidos como degradados e violentos. Ademais, a distribuição dos empregadores (estabelecimentos) e dos empregos no espaço urbano também reforça os efeitos adversos da segregação.

Para analisar essa distribuição, os dados da Relação Anual de Informações Socias (RAIS) sistematizados por Regiões Administrativas foram adaptados à tipologia socioespacial antes mencionada, verificando-se, então, que, como em outras grandes cidades brasileiras, é no centro comercial e nas áreas afluentes da cidade onde se concentram as oportunidades de trabalho e de obtenção de renda.

A distribuição espacial dos estabelecimentos "formais", com registro na RAIS, mostra a concentração de negócios nas regiões administrativas do Centro (tradicional) e da Orla e como são poucos os estabelecimentos empregadores nas RAs densamente povoadas do Miolo, dos Subúrbios Ferroviários e na RA de Valéria, área de expansão para o interior, às margens da BR 324, em direção aos municí- 

mações do mapa sobre a tipologia socioespacial de 2000 (Mapa 1) com a distribuição dos estabelecimentos por Regiões Administrativas em 2010 (Mapa 2), observa-se que a RAs da Pituba, Barra e Rio Vermelho correspondem às áreas classificadas como do tipo superior ou médio superior, e que as RAs de Tancredo Neves e Pau da Lima, Cajazeiras, Subúrbios Ferroviários e Valéria ficam nas áreas classificadas como do tipo popular inferior em 2010, que concentram os trabalhadores manuais de baixa renda, os prestadores de serviços menos qualificados, os trabalhadores domésticos e biscateiros.

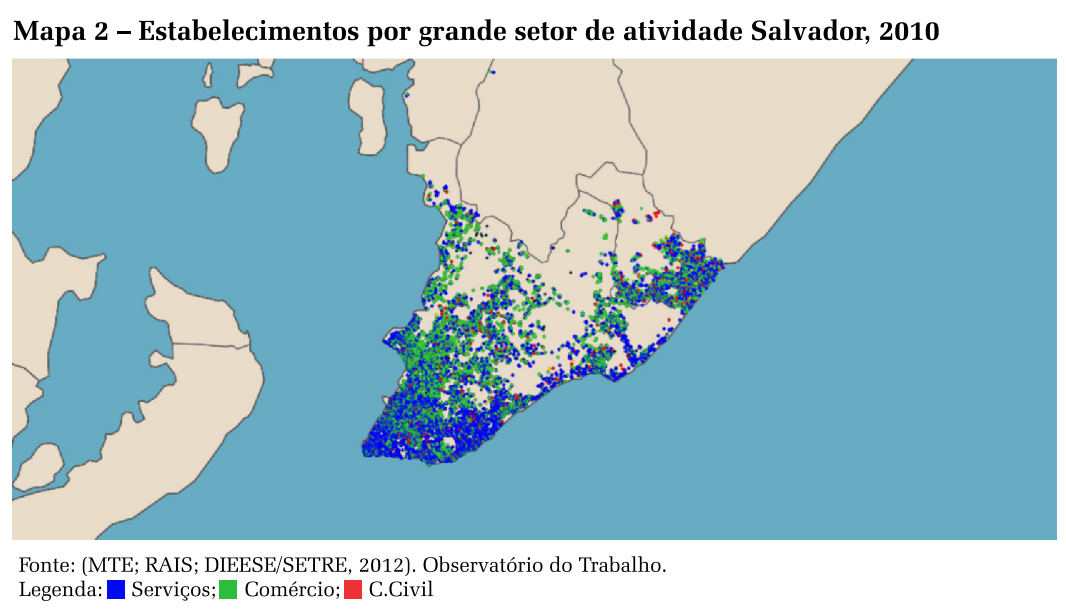

pios industriais vizinhos. Cotejando as infor-

habitados pelos estratos médio e popular. Os estabelecimentos da construção civil, bem menos numerosos, estão espalhados pelo território, com destaque para as áreas da Orla e do Miolo, que vêm concentrando investimentos públicos e privados.

Os empreendimentos de serviços organizados empresarialmente estão localizados, sobretudo, nas áreas próximas ao seu mercado consumidor (famílias de renda média e alta), grandes concentrações de trabalhadores e de empresas. Nas demais RAs, tais atividades, sobretudo os serviços pessoais, tendem a apresentar um elevado nível de informalidade. Já os estabelecimentos comerciais formalizados, embora também desigualmente distribuídos no espaço urbano, têm forte presença em alguns espaços de ocupação mais antiga e consolidada dos tipos médio e popular como as RAs de Liberdade, São Caetano, Itapagipe e Cabula. Aparecem também, em maior proporção, em RAs mais homogeneamente pobres, o

A concentração de estabelecimentos é especialmente acentuada nas atividades de serviços, que geram a maior parte dos empregos formais em Salvador: 65\% deles estão localizados em apenas quatro das dezoito regiões administrativas (as da Pituba-Costa Azul, Centro, Barra e Brotas, espaços que podem ser classificados como do tipo médio e médio superior), e $80 \%$ em sete delas (quando computadas as regiões administrativas do Rio Vermelho, Itapuã e Boca do Rio/Patamares, de composição similar), com os demais estabelecimentos pulverizados nos outros espaços da metrópole, o que é coerente com a composição socioeconômica das mencionadas regiões. $\mathrm{O}$ comércio é mais bem distribuído espacialmente, com forte presença em espaços densamente que parece revelar uma tendência recente de expansão desse tipo de negócio nessas áreas, puxada, inclusive, pelas grandes redes de supermercados e do comércio varejista, que têm se voltado para essa faixa do mercado consumidor, uma das que mais se expandem e que apresentam ganhos salariais reais e acesso crescente a crédito.

A distribuição desigual da atividade econômica no espaço urbano vai se traduzir na concentração dos empregos formais em algumas regiões, de modo desproporcional à distribuição da população. Esse desajuste entre a concentração dos empregos e da população fica patente na Tabela 1, em especial no indicador: razão postos de trabalho/mil habitantes. Na RA Centro, que corresponde à área de ocupação 
mais antiga da cidade e que sediava, até os anos 1970, o centro administrativo e econômico da capital baiana, o número de postos de trabalho formais (20,3\% do total) é superior ao da população residente (apenas 3,5\%), configurando a situação mais comum de um centro urbano que já perdeu, em muitos trechos, a função residencial. A permanência dessa concentração no centro antigo vai beneficiar os moradores das regiões mais próximas e (ou) mais bem servidas de vias de acesso a essa área.

Tabela 1 - População e postos de trabalho por Regiões Administrativas Salvador 2010*

\begin{tabular}{|c|c|c|c|}
\hline Regióes Administrativas & $\begin{array}{c}\text { Pessoas } \\
\text { residentes }\end{array}$ & $\begin{array}{c}\text { Postos de } \\
\text { trabalho }\end{array}$ & $\begin{array}{c}\text { Razão postos de } \\
\text { trabalho/mil }\end{array}$ \\
\hline
\end{tabular}

\begin{tabular}{|c|c|c|c|c|c|}
\hline & $\mathbf{N}$ & $\%$ & $\mathbf{N}$ & $\%$ & habitantes \\
\hline \multicolumn{6}{|c|}{$\begin{array}{l}\text { De tipo predominantemente } \\
\text { médio ou médio superior }\end{array}$} \\
\hline Centro & 100.232 & 3,5 & 143.498 & 20,3 & $1.431,7$ \\
\hline Pituba - Costa Azul & 184.298 & 6,4 & 136.783 & 19,3 & 742,2 \\
\hline Barra & 95.348 & 3,3 & 46.856 & 6,6 & 491,4 \\
\hline Itapuã & 235.612 & 8,1 & 86.623 & 12,2 & 367,7 \\
\hline Boca do Rio - Patamares & 118.334 & 4,3 & 18.041 & 5,4 & 321,5 \\
\hline Brotas & 209.112 & 7,3 & 58.724 & 8,3 & 280,8 \\
\hline Rio Vermelho & 133.571 & 4,6 & 31.154 & 4,4 & 233,2 \\
\hline \multicolumn{6}{|c|}{$\begin{array}{l}\text { De tipo predominantemente } \\
\text { médio/popular }\end{array}$} \\
\hline Itapagipe & 172.921 & 6,0 & 23.163 & 3,3 & 134,0 \\
\hline Cabula & 170.113 & 5,9 & 21.516 & 3,0 & 126,5 \\
\hline Liberdade & 172.685 & 6,0 & 16.947 & 2,4 & 98,1 \\
\hline São Caetano & 212.648 & 7,3 & 16.235 & 2,3 & 76,3 \\
\hline \multicolumn{6}{|c|}{$\begin{array}{l}\text { De tipo predominantemente } \\
\text { popular/popular inferior }\end{array}$} \\
\hline Valéria & 65.073 & 2,2 & 10.698 & 1,5 & 164,4 \\
\hline Pau da Lima & 264.017 & 9,1 & 29.145 & 4,1 & 110,3 \\
\hline São Caetano & 212.648 & 7,3 & 16.235 & 2,3 & 76,3 \\
\hline Tancredo Neves & 245.230 & 8,5 & 18.284 & 2,6 & 74,6 \\
\hline Subúrbio & 290.017 & 10,0 & 19.949 & 2,8 & 68,8 \\
\hline Cajazeiras & 162.687 & 5,6 & 5.460 & 0,8 & 33,6 \\
\hline Ilhas & 6.434 & 0,2 & - & - & - \\
\hline
\end{tabular}

Fonte: (MTE; RAIS; DIEESE/SETRE, 2012). Observatório do Trabalho.

*Como a área das regiões administrativas não se confunde com a das AEDS, a classificação de sua composição social é aproximada.

No restante do território, os empregos se concentram, sobretudo, nos espaços da Orla, predominantemente ocupadas pela população de renda média-alta e alta, ou se situam na proximidade dessas concentrações. A Região Administrativa Pituba-Costa Azul, que ocupa a faixa interior da costa e onde está localizado o moderno centro comercial e de serviços da capital (Iguatemi, Av. Tancredo Neves), apresenta a segunda maior razão empregos/mil hab. (742,2). Nela, eram encontrados 19,3\% dos empregos formais da cidade em 2010; nas RAs Barra (6,6\% dos empregos), Rio Vermelho $(4,4 \%)$, Boca do Rio-Patamares (5,4\%) e três outras RAs da Orla, outros 16,4\%. A RA Itapuã, onde está localizado o Centro Administrativo, com a maior parte dos empregos da esfera estadual e grande número de órgãos federais, respondia por $12,2 \%$ dos empregos existentes. Longe da Orla, encontrava-se a RA de Brotas, com $8,3 \%$ dos postos de trabalho da capital. Juntas, essas sete RAs concentravam, em 2010, $76,5 \%$ dos empregos da cidade e apenas $37,1 \%$ da sua população.

A outra face dessa concentração fica visível nas RAs localizadas no Miolo (Pau da Lima, Tancredo Neves, Cabula, Cajazeiras e Ipitanga), na RA de Valéria e nos Subúrbios, como foi dito, espaços predominantemente povoados pelos mais pobres. Nessas sete RAs, residiam 43,7\% dos habitantes de Salvador em 2010, e eram encontrados apenas 15,6\% dos empregos formais do município, revelando mercados de trabalho locais restritos e a presença de elevados níveis de informalidade.

A concentração dos empregos, sobretudo nas RAs do Centro, da Pituba-Boca do Rio e de Brotas, - as três maiores "bacias de emprego formal" da cidade -, ocorre em quase todas as atividades, ao contrário da RA de Itapuã, cujo destaque se deve à concentração de empregos 
públicos no Centro Administrativo.

Essas regiões não só apresentam elevados percentuais no total de estabelecimentos e de empregos formais como se destacam por concentrar quase todos os tipos de postos de trabalho, considerados os grupos ocupacionais e os níveis de remuneração. São "bacias de emprego" para todos os perfis de trabalhadores, o que só contribui para ampliar o seu poder de atração de novos empreendimentos de todos os tipos, de mais postos de trabalho e de contingentes cada vez maiores de trabalhadores em detrimento de outros espaços urbanos, muito embora as deseconomias de escala geradas pelos congestionamentos estimulem o surgimento de novos espaços de concentração de atividades, em especial aquelas voltadas para o consumo empresarial e dos segmentos de mais alta renda. Esse movimento, no entanto, não altera a desvantagem das áreas que concentram os segmentos mais pobres da população. Apenas novos espaços são produzidos pela indústria imobiliária reproduzindo o padrão de segregação espacial, a exemplo da expansão recente na Avenida Paralela, mais próxima do Miolo, mas igualmente apartada da ocupação pré-existente, inclusive pelo traçado viário, concebido para não integrar os novos investimentos à ocupação popular da vizinhança. .

Como já foi assinalado, como parte de uma "geografia de oportunidades", essa concentração de postos de trabalho socialmente protegidos nas áreas ocupadas pelos estratos médios e médios superiores da estrutura sócio-ocupacional de Salvador se soma a efeitos da moradia em áreas periféricas e segregadas, o que contribui para dificultar a incorporação ao mercado de trabalho dos moradores dessas últimas áreas, ampliando a vulnerabilidade ocupacional de seus segmentos mais frágeis (jovens, negros, mulheres).

Alguns indicadores baseados no Censo de 2010 evidenciam as desvantagens da população residente nos espaços do tipo "popular", apesar das melhorias ocorridas na década de 2000. Em primeiro lugar, como se observa pela Tabela 2, eles registram uma maior frequência de jovens de 16 a 29 anos que não estudam, não procuram emprego e nem trabalham, denominados de "Nem-Nem".

\begin{tabular}{|c|c|c|c|c|}
\hline \multirow[b]{2}{*}{ Características selecionadas } & \multirow{2}{*}{$\begin{array}{c}\text { Município } \\
\text { de Salvador }\end{array}$} & \multicolumn{3}{|c|}{ Áreas segundo tipologia } \\
\hline & & Popular & Médio & $\begin{array}{c}\text { Médio } \\
\text { superior }\end{array}$ \\
\hline Total & 15,2 & 16,7 & 15,2 & 11,7 \\
\hline \multicolumn{5}{|l|}{ Sexo } \\
\hline Homens & 11,8 & 12,7 & 11,6 & 10,0 \\
\hline Mulheres & 18,4 & 20,5 & 18,7 & 13,1 \\
\hline \multicolumn{5}{|l|}{ Cor ou raça** } \\
\hline Negra & 15,5 & 16,5 & 15,6 & 12,0 \\
\hline Não negra & 13,3 & 15,9 & 13,6 & 11,0 \\
\hline \multicolumn{5}{|l|}{ Escolaridade } \\
\hline Sem instrução e fundamental incompleto & 23,1 & 24,3 & 22,4 & 18,4 \\
\hline Fundamental completo e médio incompleto & 11,3 & 11,7 & 11,6 & 8,6 \\
\hline Médio completo e superior incompleto & 14,9 & 15,9 & 14,7 & 13,2 \\
\hline Superior completo & 7,6 & 6,5 & 7,5 & 8,0 \\
\hline
\end{tabular}

Trata-se de um fenômeno associado aos novos padrões de transição para a idade adulta, que vem sendo acentuado pelas mudanças no mercado de trabalho e que, embora se manifeste em todos os segmentos sociais, tem determinantes e consequências distintas em cada um deles. Entre os mais pobres, sobretudo entre os homens, os elevados percentuais de "Nem-Nem" sugerem o distanciamento dos principais integradores socais - o trabalho e a escola -, o qual raramente pode ser compensado pela família, também ela fragilizada pela precariedade e instabilidade da inserção de 
seus membros no mercado de trabalho.

Os jovens nessa situação geralmente abandonaram a escola precocemente, antes de completar o Ensino Médio, quando não o Ensino Fundamental, o que amplia as suas dificuldades de acesso a um posto de trabalho, formal ou informal, e os expõe à ação de agentes que os colocam em situação de risco, inclusive de risco de vida (como as quadrilhas e gangues, ligadas ou não ao tráfico de drogas, que frequentemente controlam esses espaços em que residem e capturam os jovens com alternativas de obtenção de renda e de prestígio junto à comunidade e, sobretudo, a seus pares e às jovens e os agentes repressores do Estado) e que estigmatizam a população aí residente, principalmente os homens jovens e negros, que passam a ser tratados como criminosos de alta periculosidade.

Em Salvador, em 2010, a proporção de jovens "Nem-Nem" residentes nas áreas classificadas como populares é sistematicamente mais elevada do que a registrada em áreas que concentram os estratos médio e médio superior (e superior), independentemente dos atri-
Média Superior, o mesmo ocorrendo no caso dos Negros e dos Sem Instrução/Fundamental Incompleto.

A Tabela 3, que apresenta as taxas específicas de desemprego segundo as variáveis mais relevantes na sua determinação (idade, sexo, escolaridade e cor), também revela a importância do efeito território sobre a inserção no mercado de trabalho: em todos os casos jovens, mulheres, negros e pessoas com baixa escolaridade -, a exposição ao desemprego é mais elevada nas áreas classificadas como populares do que nas áreas médias e, sobretudo, naquelas do tipo média superior.

Nos espaços do tipo popular, a taxa média de desemprego alcançava $16 \%$ contra $7,1 \%$ nos espaços classificados como médio-superior; as mulheres aí residentes tinham 21,3\% de chances de estar desempregadas, contra $8,3 \%$ dentre as que moravam nas áreas médio-superior; os negros que residiam nas áreas populares apresentavam uma taxa de desemprego de $16,2 \%$ em 2010, contra $8,2 \%$ dos que residiam nos espaços do tipo médio superior. As desigualdades eram igualmente marcantes butos de sexo, cor e escolaridade, traduzindo o efeito do local de residência.

Com uma taxa 䢓 vens na condição de "Nem-Nem", contra 15,2\% nas áreas onde predominam os estratos médios e 11,7\% $\dot{s}$ naquelas classificadas como Médio Superior, esses espaços tendem a acentuar o efeito de outros atributos pessoais. Assim, a proporção de mulheres "Nem-Nem" é muito mais elevada nas áreas Populares, 60 anos ou mais na Pequena Média e na $\quad \begin{aligned} & \text { *Nente: Elaboração das autoras, a partir de tabulaçóes especiais do IBGE/Censo Demográfico (2010) } \\ & \text { "Netos e pardos; não negra = brancos, indígenas e amarelos, cf. classificação do IBGE. }\end{aligned}$ 
entre pessoas com a mesma escolaridade ou no mesmo grupo etário conforme o local de moradia, como se vê na Tabela 3.

Finalmente, os dados apresentados na Tabela 4, relativos aos ocupados em atividades informais, sugerem que as mudanças ocorridas no mercado de trabalho regional, na primeira década do século XXI, tiveram impactos extremamente positivos sobre os homens, inclusive aqueles com baixa escolaridade e mais jovens. Desse modo, ao contrário do esperado, as taxas de informalidade - um indicador de inserção precária - dos moradores das áreas do tipo popular chegam a ser, em alguns casos, inferiores àquelas dos residentes nos espaços do tipo médio superior. A explicação para essa redução da informalidade entre os segmentos mais pobres é explicada, em boa medida, pelas oportunidades abertas pela ativação do mercado de trabalho formal nos anos 2000 e pelo perfil de grande parte dos empregos aí criados: postos de trabalho na construção civil (um espaço de entrada no mercado de trabalho

Tabela 4 - Percentual de ocupados informais* segundo características pessoais Salvador 2010

\begin{tabular}{|c|c|c|c|c|}
\hline \multirow[b]{2}{*}{ Características selecionadas } & \multirow{2}{*}{$\begin{array}{c}\text { Município } \\
\text { de Salvador }\end{array}$} & \multicolumn{3}{|c|}{ Áreas segundo tipologia } \\
\hline & & Popular & Médio & $\begin{array}{l}\text { Médio } \\
\text { superior }\end{array}$ \\
\hline Total & 41,4 & 44,2 & 41,4 & 36,3 \\
\hline \multicolumn{5}{|l|}{ Sexo } \\
\hline Homens & 35,3 & 35,5 & 35,9 & 33,7 \\
\hline Mulheres & 48,4 & 55,1 & 47,8 & 38,8 \\
\hline \multicolumn{5}{|l|}{ Cor ou raça** } \\
\hline Negra & 42,6 & 44,5 & 42,0 & 38,6 \\
\hline Não negra & 37,2 & 42,3 & 38,8 & 33,2 \\
\hline \multicolumn{5}{|l|}{ Escolaridade } \\
\hline Sem instrução e fundamental incompleto & 62,1 & 60,6 & 62,9 & 67,0 \\
\hline Fundamental completo e médio incompleto & 50,5 & 50,1 & 49,9 & 55,1 \\
\hline Médio completo e superior incompleto & 32,5 & 31,2 & 31,5 & 37,7 \\
\hline Superior completo & 23,0 & 18,4 & 19,4 & 25,3 \\
\hline \multicolumn{5}{|l|}{ Idade } \\
\hline De 10 a 15 anos & 92,7 & 92,6 & 93,0 & 91,6 \\
\hline De 16 a 29 anos & 39,3 & 39,8 & 37,7 & 41,6 \\
\hline De 30 a 59 anos & 40,7 & 44,5 & 41,5 & 32,8 \\
\hline 60 anos ou mais & 53,1 & 60,2 & 55,1 & 44,5 \\
\hline
\end{tabular}

Fonte: Elaboração das autoras, a partir de tabulações especiais do IBGE/Censo Demográfico (2010).

${ }^{*}$ Ocupados informais = trabalhadores domésticos, conta-própria, empregados sem carteira, não remunerados e trabalhadores na produção para o próprio consumo.

${ }^{* *}$ Negra = pretos e pardos; não negra = brancos, indígenas e amarelos, cf. classificação do IBGE. de homens jovens menos escolarizados) no comércio e nos serviços de apoio, onde se multiplicaram os empregos com remuneração em torno de um salário mínimo. Por outro lado, a expansão recente da economia aprofundou a flexibilização, precarização ou informalização das formas de contratação dos trabalhadores com maiores salários e mais escolarizados, residentes predominantemente nas áreas do tipo Médio Superior, um movimento que assumiu, sobretudo, a forma de fuga do assalariamento (PJ, conta própria, etc.) com vistas à redução dos custos trabalhistas (encargos e benefícios).

\section{FINALIZANDO}

Reconhecendo a segregação socioespacial como uma das características marcantes das grandes cidades, com impactos adversos sobre a reprodução das desigualdades e sobre as condições de vida da maioria da sua população, este texto se propôs a discutir as relações entre essa segregação e o acesso ao mercado de trabalho.

Para tanto, ele se reportou, inicialmente, aos efeitos mais amplos da segregação sobre o acesso a bens e serviços e às oportunidades, refletindo, a seguir, sobre a influência da localização dos postos de trabalho no território urbano quanto ao o acesso às oportunidades ocupacionais. Levando em conta as condições do mercado de trabalho e o padrão de segregação espacial que prevalecem atualmente em Salvador, constatou-se, como seria de esperar, 
que a desigualdade social é o fator preponderante na ocupação do território urbano, o que leva o comércio, os serviços e os postos de trabalho a se concentrarem na área central e em alguns poucos espaços da cidade, seguindo os deslocamentos e a proximidade das camadas de maior renda.

Assim, as grandes concentrações da pobreza urbana - Subúrbios, Valéria e a maior parte do território chamado Miolo (ver Mapa 3) - apresentam reduzido número de estabelecimentos e empregos formais, fato que dificulta o acesso de seus moradores a esses postos de trabalho mais valorizados porque socialmente protegidos. Tais dificuldades são ainda mais acentuadas no caso dos grupos vulneráveis - a exemplo dos jovens, negros e menos escolarizados - que, além de barreiras colocadas pela distância, pela desinformação e pelos custos do deslocamento, se defrontam com preconceitos de toda ordem e com o estigma de residir em áreas segregadas, percebidas como associadas à violência e à criminalidade.

Em Salvador como em outras cidades, a distribuição espacial dos empreendimentos e dos postos de trabalho socialmente protegidos contribui de forma relevante para os impactos adversos do processo de segregação, uma vez que os moradores das áreas pobres ficam aprisionados em espaços que não oferecem maio- fora do domicílio e a ele retornavam diariamente, nas principais capitais brasileiras. No caso de Salvador, apenas 39,4\% desses trabalhadores despendiam até meia hora, enquanto que $38,6 \%$ gastavam de meia até uma hora e $22,1 \%$ mais de uma hora. Em São Paulo e no Rio de Janeiro, as duas maiores metrópoles brasileiras, o percentual de moradores que gastava mais de uma hora no deslocamento entre casa e trabalho era de, respectivamente, $31,1 \%$ e $25,3 \%$. Todas as demais metrópoles pesquisadas apresentam percentuais mais baixos de trabalhadores forçados a deslocamentos muito demorados: Belo Horizonte 16,5\%, Recife 11,3\%, e Porto Alegre 10\%. Essas diferenças são determinadas por vários fatores, como a extensão do tecido urbano, a qualidade da rede viária e dos transportes de massa e, também, pela maior ou menor concentração das atividades produtivas no espaço metropolitano.

Sem uma política pública voltada para a desconcentração das atividades produtivas no território, o desajuste territorial entre lugares de residência e trabalho das camadas mais pobres pode, inclusive, se acentuar, uma vez que as áreas que se beneficiam da concentração de negócios reforçam sua posição de espaços prioritários para investimentos públicos e valorização imobiliária, apesar dos impactos adversos sobre a vida cotidiana da população e o funcionamento de toda cidade, notadamente em termos de congestionamento do trafego e mobilidade urbana.

Desse modo, a valorização dessas áreas "nobres" e a maior oferta de serviços públicos e privados ai existentes são também resultantes do trabalho de batalhões de trabalhadores "de fora”, que não se beneficiam dessa concentração nem podem usufruir da abundância de bens, serviços e oportunidades que elas oferecem. Pelo contrário, os postos de trabalho formais a que têm acesso geralmente pagam baixos salários, porque a maior parte desses trabalhadores se encontra em posição de desvantagem na disputa dos melhores empregos e oportunidades existentes nessas áreas. 
Esses trabalhadores, que moram no "outro lado" da cidade e em áreas segregadas, têm, em média, menor número de anos de estudo, e os serviços educacionais que acessam são qualitativamente inferiores àqueles desfrutados pelos residentes nas áreas de média alta e alta renda; além disso, dispõem de menos informações sobre o mercado de trabalho e as oportunidades de acesso à renda, arcando com as consequências do fato de residirem em áreas desprivilegiadas e, para a maioria, muito distantes dos pontos de concentração de empregos formais.

Embora só recentemente tenham sido percebidos por parte de pesquisadores, esses fenômenos vêm adquirindo certa visibilidade e entrando na agenda pública. Nesse sentido é que começa a ser discutida a necessidade de se implementarem políticas urbanas orientadas para disseminar as atividades de comércio e serviços no espaço metropolitano e multiplicar os subcentros como elementos de reequilíbrio e de relações entre os diversos fragmentos e áreas, conferindo urbanidade a toda a cidade. Políticas desse tipo, se aliadas a iniciativas para a indução de espaços de moradia menos homogêneos, que abram espaço para a convivência, em uma mesma vizinhança, entre as diferentes camadas sociais que habitam a metrópole, são indispensáveis para a redução da segregação socioespacial e, logo, para o enfrentamento da vulnerabilidade e dos estigmas que vitimizam os segmentos mais pobres da população metropolitana.

Recebido para publicação em 26 de junho de 2015 Aceito em 22 de setembro de 2016

\section{REFERÊNCIAS}

ANDRADE, L. T.; SILVEIRA, L. S. Efeito território: explorações em torno de um conceito sociológico. Civitas, Porto Alegre, n. 2, v. 13, p. 381-402, maio/ago.2013.

ARANTES, R. de A. Enquanto isso, lá no miolo da cidade... O papel das desigualdades socioespaciais na ampliação da vulnerabilidade social. 2007. Monografia (Trabalho de conclusão de curso) - Departamento de
Sociologia, Universidade Federal da Bahia, Salvador, 2007.

BAHIA. Departamento Intersindical de Estatística e Estudos Socioeconômicos (DIEESE). Secretaria do Trabalho, Emprego, Renda e Esporte (SETRE). Observatório do Trabalho. 2010. Disponível em : <http://geo.dieese.org. br/bahia/>. Acesso em: 07 jul. 2012.

BORGES, A. Desestruturação do mercado de trabalho e vulnerabilidade social: a Região Metropolitana de Salvador na década de 90. 2003. 374 f. Tese (Doutorado) - Faculdade de Filosofia e Ciências Humanas, Universidade Federal da Bahia, Salvador, 2003.

BOURDIEU, P. Efeitos do Lugar. In: BOURDIEU, P. (Org.). A miséria do mundo. Petrópolis: Vozes, 1997. p. 159-175.

BURGOS, M. T. B. Segregação urbana e segregação institucional. In: CONGRESSO BRASILEIRO DE SOCIOLOGIA, 14., Rio de Janeiro. Anais... Rio de Janeiro: [S.n.], 2009.

CARVALHO, I. M. M. de; BORGES, A. A Região Metropolitana de Salvador na transição econômica: estrutura produtiva e mercado de trabalho. In: CARVALHO, I. M. M. de; PEREIRA, G. C. Salvador: transformações na ordem urbana. Rio de Janeiro: Letra capital: Observatório das metrópoles, 2014. p. 77-108.

- PEREIRA, G. C. As "cidades" de Salvador. In:

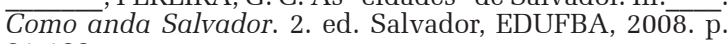
81-108.

CUNHA, J. M. P. da, JACOB, A. A. E. Segregação socioespacial e inserção no mercado de trabalho na Região Metropolitana de Campinas. Revista brasileira de estudos de população, Rio de Janeiro, v. 27, n. 1, p. 115-139, 2010.

FLORES, C. Consequências da segregação residencial: teoria e métodos. In: CUNHA. J. M. P. (Org.). Novas metrópoles paulistas: população, vulnerabilidade e segregação. Campinas: NEP: UNICAMP, 2006.

FONSÊCA, M. de L. P. Centralidades e políticas urbanas na cidade de São Paulo. In: SEMINÁRIO INTERNACIONAL RII, 12., Belo Horizonte. Anais... Belo Horizonte: [S.n.], 2012.

GOMES, S.; AMITRANO, C. Local de moradia na metrópole e vulnerabilidade ao emprego e desemprego. In: MARQUES, E.; TORRES, H. (Org.). São Paulo: segregação, pobreza e desigualdades sociais. São Paulo: Ed. SENAC, 2005.

JARGOWSKY, P. A. Take the money and run: economic segregation in U.S. metropolitan areas. American Sociological rewiew, n. 61, 1996. Disponível em: <http:/ www.jstor.org/stable/2096304 >. Acesso em: 14 out. 2014.

KAZTMAN, R. Seducidos y abandonados: elaislamento social de lós pobres urbanos. Revista da CEPAL, Santiago, n. 75, p. 171-189, 2001.

; RETAMOSO, A. Segregación espacial, empleo y $\overline{\text { pobreza }}$ en Montevideo. Revista da CEPAL, v. 85, p. 131148, abr. 2005.

KOWARICK, L. A espoliação urbana. Rio de Janeiro: Paz e Terra, 1980.

MARQUES, E. Redes sociais, segregação e pobreza. São Paulo: UNESP, 2010.

MOLINATTI, F. Segregación residencial e inserción laboral em laciudad de Córdoba. EURE: Revista latinoamericana de estudios urbano regionales, Santiago, n. 117, p. 117$145,2013$.

PRETECEILLE, E. A evolução da segregação social e das desigualdades urbanas: o caso da metrópole parisiense nas últimas décadas. Caderno CRH: revista do Centro de recursos humanos, Salvador, n. 36, p. 27-48, 2003.

Segregação urbana. In: IVO, A. B. L. (Coord.). Dicionário temático desenvolvimento e questão social. São 
Paulo: Annablume, 2013. p. 442-448.

RIBEIRO, L. C. de Q.; KAZTMAN, R. A cidade contra a escola? Segregação urbana e desigualdades educacionais em grandes cidades da América Latina. Rio de Janeiro: Letra Capital: FAPERJ, 2008.

RIBEIRO, L. C. de Q. et al. (Org.). Desigualdades urbanas, desigualdades escolares. Rio de Janeiro: Letra Capital: Observatório das metrópoles, 2010. 334 p.

RIBEIRO, M. G. et al. Mercado de trabalho e efeito território das principais metrópoles brasileiras. In: SEMINÁRIO DA RED IBEROAMERICANA DE INVESTIGADORES SOBRE GLOBALIZACION Y TERRITORIO, 13., 2014, Salvador. Anais... Salvador: [S.n.], 2014.

SABATINI, F.; WORMALD, G.; RASSA, A. (Ed.). Segregación de la vivienda social: ocho conjuntos em Santiago, Concepcion y Talca. Santiago: Instituto de Estudios Urbanos y Territoriales de Pontificia Universidad Catolica de Chile, 2013. 203-242 p.

SERAVI, G. A. Segregación urbana y desigualdades em La ciudad de Mexico. EURE: Revista latinoamericana de estudios urbano regionales, Santiago, v. 34, n. 103, p. 93110, dec. 2008.
SOLIS, P.; PUGA, I. Efectos del nível socioeconômico de la zona de residência sobre el proceso de estratificación social en Monterrey. Estudios demográficos y urbanos, v. 26, n. 2, p. 233-265, 2011.

SMALL, M.; NEWMAN, K. Urban poverty after the truly desavantaged: therediscoveryofthe Family, yheneighborhoodandculture. Anual rewiewof Sociology, v. 27, p. 23-45, 2001. Disponível em: <http/www.jstor.org. stable2678613>. Acesso em: 14 out. 2014.

TELLES, V. S.; CABANES, R. Nas tramas da cidade: trajetórias urbanas e seus territórios. São Paulo: Associação editorial humanitas, 2006. $439 \mathrm{p}$.

VIGNOLI, J. R. Movilidad cotidiana, desigualdade social y segregación residencial em cuatro metropolis da America Latina. EURE: Revista latinoamericana de estudios urbano regionales, Santiago, v. 34, n. 103, p. 49-71, dec. 2008.

WACQUANT, L. Da América como utopia às avessas. In: BOURDIEU, P. (Org.). A miséria do mundo. Petrópolis: Vozes, 1997. p. 167-175.

. As duas faces do gueto. São Paulo: Boitempo, 2008.

WILSON, J. The truly disavantaged. Chicago: The Uinversity of Chicago Press, 1987. 


\section{REVISITING THE EFFECTS OF PLACE: segregation and access to labor market in a Brazilian metropolis}

\author{
Ângela Borges \\ Inaiá Carvalho
}

\section{REVISITER LES EFFETS DE LIEU: ségrégation et accès au marché du travail dans une métropole brésilienne}

Ângela Borges

Inaiá Carvalho
This article proposes to discuss the so-called "territory effect" comprehended as the benefits or losses that affect some social groups in consequence of its localization in the urban space. In order to do so, it is analyzed how the place of residence interferes with the access and the incorporation in the labor market based on a research made in the third largest Brazilian capital, the city of Salvador. Firstly, this article directs itself to the previous literature about this phenomenon and, then, to the current discussions about the adverse impacts of segregation. It is also presented the specificities of the city of Salvador from the point of view of the occupation and the differentiation of its territory and of its occupational conditions. Finally, based on RAIS and Censo 2010 special tabulations properly spatialized, this study emphasizes how the "territory effect" operates adversely to the population that is concentrated in the poor periphery, more distant and less occupied, in addition to other factors. This fact also contributes to the occupational vulnerability of their residents and to the reproduction of social inequalities.

KEYwORDS: Sociospatial Segregation. "Territory effect”. Labor and unemployment. Salvador.
Cet article se propose de discuter le dénommé "effet territoire"entendu comme représentant les bénéfices ou les préjudices qui touchent quelques groupes sociaux à cause de leur localisation dans l'espace urbain. On y analyse comment le local de résidence influence l'accès et l'insertion dans le marché du travail à partir d'une recherche effectuée dans la ville de Salvador, troisième plus grande capitale brésilienne.Pour ce faire, on commence par ce qui a été écrit au sujet de ce phénomène et les discussions courantes sur les impacts nocifs de la ségrégation. Les spécificités de Salvador sont ensuite présentées du point de vue de l'occupation et de la différenciation de son territoire et de ses conditions d'occupation. Enfin, sur la base de croisements spécifiques de la RAIS et du recensement de 2010 dûment spécialisés, le texte montre combien "l'effet territoire" a des effets négatifs pour les populations qui se concentrent dans les banlieues pauvres, plus éloignées et moins équipées et s'ajoutent à d'autres facteurs pour contribuer à une vulnérabilité occupationnelle de ses habitants ainsi qu'à la reproduction d'inégalités sociales.

Mots-CLÉs: Ségrégation socio-spatiale. "Effet territoire”. Emploi et chômage. Salvador. 
